\title{
Evaluation of Total Phenolic Contents and Antioxidant Activity of Carrot Callus Extracts as Affected by Phenylalanine Precursor
}

\author{
Nermeen M. Arafa, Mona M. Ibrahim and Usama Ibrahim Aly* \\ Department of Plant Biotechnology, Genetic Engineering and Biotechnology Division, \\ National Research Center, El-Buhouth St., (P.O. Box 12622), Dokki, Cairo, Egypt
}

Key words: Daucus carota, Phenylalanine, Antioxidant activity, $\beta$-carotene bleaching, Total phenolics

\begin{abstract}
Carrot (Daucus carota) is a valuable plant with both therapeutic and horticultural potential. Stem, petiole and root derived calli of carrot were obtained on solid MS supplemented with $1 \mathrm{mg} / \mathrm{l} \mathrm{BAP}+2 \mathrm{mg} / \mathrm{l} \mathrm{NAA}$. Callus cultures supplemented with different L-phenylalanine (PHE) concentrations under light and dark conditions were evaluated for their antioxidant activity and total phenolic contents. The authors showed that PHE supplementation in Daucus carota cultures was necessary to raise the extraction yield percentage. Antioxidant assays such as DPPH scavenging activity and $\beta$-carotene bleaching have been carried out. In DPPH system, callus extracts from different explants grown under light conditions displayed lower DPPH radical scavenging activity at all PHE levels compared with that grown under dark conditions. Moreover, under both light and dark conditions callus cultures grown on MS supplemented with 1 $\mathrm{mg} / \mathrm{l} \mathrm{BAP}+2 \mathrm{mg} / \mathrm{l} \mathrm{NAA}$ plus $1000 \mathrm{mg} / \mathrm{l}$ PHE were recorded to yield the maximum values as antioxidant activities. Regarding $\beta$-carotene bleaching assay, under light condition the callus extract of stem, root and petiole recorded an inhibition of linolic acid 47.9, 41.43 and 39\%) which is lower compared with dark grown cultures, respectively (52.46, 72.71 and $73.26 \%$ ). Effect of different concentrations of phenylalanine on the total phenolic content of carrot callus extract examined under light conditions varied from 0.33 to $2 \mathrm{mg} / \mathrm{g}$ DW and 0.51 to $3.69 \mathrm{mg} / \mathrm{g}$ DW under dark conditions as expressed
\end{abstract}

*Authors for correspondence: <usamajp@yahoo.com>. 
by gallic acid equivalent (GAE). Our results have demonstrated that Daucus carota can be further extended to exploit its possible application for the preservation of food products as well as a health supplement and neutraceutical.

\section{Introduction}

Carrot is among the top ten most economically important vegetable crops in the world, in terms of both area of production and market value (Rubatzky et al. 1999, Simon 2000, Fontes and Vilela 2003, Vilela 2004, FAO 2008).

Fruits and vegetables are valuable sources of health-promoting substances active in neutralization of reactive oxygen species. Among them carrot (Daucus carota L.) belongs to horticultural crops of high recognition and economic importance due to its nutritional value and high concentration of bioactive constituents (Rubatzky et al. 1999, Baranski et al. 2012).

Although carrot is not a significant source of calories in the human diet, it is a potential source of dietary nutrients, and antioxidant compounds in the form of plant pigments, including carotenoids, anthocyanins, and other flavonoids (Alasalvar et al. 2001). The health benefits of these compounds, including protection against certain forms of cancer, reduction of the risk of cardiovascular disease, and scavenging of free radicals (Van den Berg et al. 2000, Stintzing and Carle 2004), have led to consumer interest in natural products rich in carotenoids and anthocyanins.

Antioxidants are compounds that inhibit or delay the oxidation process by blocking the initiation or propagation of oxidizing chain reactions. They may function as free radical scavengers, complexes of pro-oxidant metals, reducing agents and quenchers of singlet oxygen formation (Andlauer and Furst 1998). There are two basic categories of antioxidants, namely synthetic and natural ones. Restriction on the use of synthetic antioxidants is being imposed because of their carcinogenicity (Grice 1986, Wichi 1988). Therefore, the development and utilization of more effective antioxidants of natural origin are favored (Tevfik and Kadir 2008).

Carotenoids are important micronutrients for human health (Castermiller and West 1998). The main physiological function of carotenoids is as a precursor of vitamin A (Nocolle et al. 2003). In the past decade, $\beta$-carotene has attracted considerable attention because of their possible protective effect against some types of cancers (Bast et al. 1996, Santo et al. 1996, Van 1996). Carotenoids have been linked with the enhancement of immune system and decreased risk of degenerative diseases such as cancer, cardiovascular disease, age related 
muscular degeneration and cataract formation (Mathews-Roth 1985, Bendich 1990, Krinsky 1990, Byers and Perry 1992).

Phenolics are ubiquitous plant components that are primarily derived from phenylalanine via the phenylpropanoid metabolism (Dixon and Paiva 1995). Phenolics in carrots are present throughout the roots but are highly concentrated in the periderm tissue (Mercier et al. 1994).

Until now the assessments of carrot cultivars with regard to the presence of phenolic compounds have been performed using a smaller number of cultivars which sometimes of unknown origin (Singh et al. 2001) and often restricted to only individual accession of a given root color or location (Bajaj et al. 1980). However, the genetic background is a critical factor determining qualitative and quantitative chemical composition of the plant tissue, thus accounting for inconsistent results obtained in different research projects.

In order to enhance the synthesis of secondary metabolites, several organic compounds can be added to the culture medium (Namdeo et al. 2007). The concept is based on the idea that any compound, which is an intermediate in or at the beginning of a secondary metabolite biosynthetic route, stands a good chance of increasing the yield of the final product (Rao and Ravishankar 2002).

The aim of this work was to analyze the antioxidant activity of Daucus carota callus cultures as affected by different PHE concentrations under light and dark conditions. The antioxidant capacity was measured by DPPH and $\beta$-carotene bleaching method and the total phenolics by Folin-Ciocalteu method as gallic acid equivalent.

\section{Materials and Methods}

The seeds of Daucus carota were obtained from Vegetables Research Department, Agriculture Research Centre, Ministry of Agriculture, Dokki - Giza, Egypt. They were washed with soap and current tap water, then surface sterilized in a $70 \%$ (v/v) Et-OH for $1 \mathrm{~min}$ followed by $75 \%$ Clorox solution of household bleach (5.25\% sodium hypochlorite) with a drop of Tween-20 for 20 min with frequent agitation. After thorough washing in sterile distilled water, seeds were placed on basal MS supplemented with $0.7 \%(\mathrm{w} / \mathrm{v})$ agar, 3\% $(\mathrm{w} / \mathrm{v})$ sucrose for seed germination. The $\mathrm{pH}$ was adjusted to 5.8 before autoclaving at $121^{\circ} \mathrm{C}$ for $15 \mathrm{~min}$. The cultures were incubated under controlled light regime ( $16 \mathrm{hrs}$ photoperiod of fluorescent $45 \mu \mathrm{mol}$, cool white light tubes and $8 \mathrm{hrs}$ dark) at $25 \pm 1^{\circ} \mathrm{C}$. Within five weeks of cultivation, the in vitro growing carrot seedlings were used as a source of explants in further experiments. 
After four weeks of germination, petiole, stem and root explants were excised from in vitro growing seedlings and divided into three segments before cultured on MS supplemented with $1 \mathrm{mg} / \mathrm{l} \mathrm{BAP}+2 \mathrm{mg} / \mathrm{l}$ NAA. Cultures were kept in a growth room under the same conditions used for seed germination for three weeks and the initiated calli were sub-cultured on the same medium for maintenance and callus increment.

Derived callus from different explants were re-cultured on the same MS fortified with an amino acid precursor, L-phenylalanine (PHE), at different concentrations (500 and $1000 \mathrm{mg} / \mathrm{l}$ ). The control medium was made without precursor additives. L-phenylalanine was added to the media prior to autoclaving. Cultures were divided into two groups; the first group was incubated under a $16 \mathrm{hrs} /$ day photoperiod and the second was maintained in darkness for 4 weeks.

Fresh samples of in vitro calli cultures of petiole, stem and root explants were extracted using a method of maceration with $85 \%$ methanol for $24 \mathrm{hrs}$ at room temperature. The extracts were collected, filtered and evaporated to dryness. The residues were dissolved in $85 \%$ methanol and stored at $4{ }^{\circ} \mathrm{C}$ until further use. The percentage yield of the extract was calculated using the formula:

$$
\% \text { yield }=\frac{\text { Weight of three extract }}{\text { Weight of callus cultures }} \times 100
$$

Radical scavenging activity of plant extracts against stable 2, 2'-diphenyl 1picrylhydrazyl (DPPH) was determined by a slightly modified method of BrandWilliams et al. (1995). Radical scavenging activity (\%) was calculated by the following formula:

$\left.\operatorname{RSC}(\%)=\left[\mathrm{ADPPH}-\mathrm{A}_{\mathrm{s}}\right) / \mathrm{ADPPH}\right] \times 100$

where As is the absorbance of solution with callus extract and ADppH is the absorbance of DPPH solution.

The procedure of Mi-Yac et al. (2003) has been adapted for this assay. $\beta$ carotene $(2 \mathrm{mg})$ was dissolved in $10 \mathrm{ml}$ chloroform and to $2 \mathrm{ml}$ of this solution, linoleic acid (40 mg) and Tween $40(400 \mathrm{mg})$ were added. Chloroform was evaporated under vacuum at $40^{\circ} \mathrm{C}$ and $100 \mathrm{ml}$ of ultra-pure water was added, then the emulsion was vigorously shaken. Aliquots $(1 \mathrm{ml})$ of this emulsion were transferred into tubes containing $500 \mu \mathrm{l}$ of the extracts. The tubes were shaken and incubated at $50^{\circ} \mathrm{C}$ in water bath. The absorbance readings (at $470 \mathrm{~nm}$ ) for all samples were performed immediately $(t=0 \mathrm{~min})$ and after $120 \mathrm{~min}$ of incubation. Antioxidant activity of the extracts was evaluated in terms of $\beta$-carotene bleaching using the following formula:

$\beta$-carotene bleaching inhibition $(\%)=\left[S-C_{120} / C_{0}-C_{120}\right] \times 100$ 
where $\mathrm{C}_{0}$ and $\mathrm{C}_{120}$ are the absorbance values of the control at 0 and $120 \mathrm{~min}$, respectively, and $S$ is the sample absorbance at $120 \mathrm{~min}$.

The amount of total phenolics content was determined using the FolinCiocalteu method (Zheng and Wang 2001). A calibration curve of gallic acid was prepared, and the results were expressed as mg GAE (gallic acid equivalents/g DW).

The data were subjected to statistical analysis, employing F-test for significance at $\mathrm{p} \leq 0.05$ and computing LSD values to separate means in different statistical groups (Gomez and Gomez 1984).

\section{Results and Discussion}

Following seeds transfer to basal MS, in vitro growing Daucus carota seedlings emerged by the fourth week and used as a source of explants in further experiments. From a preliminary experiment, MS supplemented with $1 \mathrm{mg} / \mathrm{l}$ $\mathrm{BAP}+2 \mathrm{mg} / \mathrm{l} \mathrm{NAA}$, was figured out as the best for callus induction percentage from stem, petiole and root explants of carrot (Fig. 1). A friable and yellow colored callus within three weeks of inoculation was observed. Initiated callus was sub-cultured for getting enough stock which was used for conducting various tests and experiments. Similar results of callus induction in carrot have been reported where plant growth regulators (PGRs) were needed for callus induction (Widholm 1984, Michler and Lineberger 1987, Roustan et al. 1990).

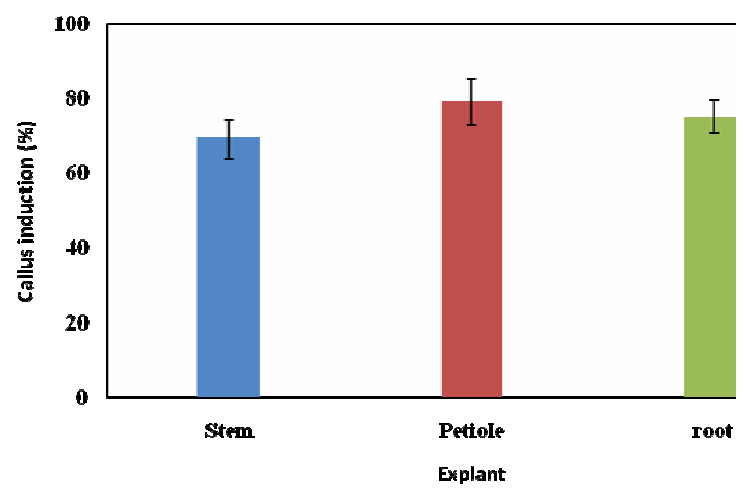

Fig. 1. Callus induction percentage of Daucus carota on MS supplemented with $1 \mathrm{mg} / \mathrm{l}$ BAP $+2 \mathrm{mg} / \mathrm{l} \mathrm{NAA}$. Values are mean \pm standard error of three replicates.

Assessment of extraction yield percentage (w/w) of Daucus carota cells in media containing various concentrations of phenylalanine (PHE), or PHE-free medium as a control, under light and dark conditions is presented in Table 1. In the control cultures and cultures supplemented with PHE, calli derived from petiole explants gave maximum percentage of extraction yield followed by stem 
and root explants which recorded minimum value under light and dark conditions. The addition of 500 or $1000 \mathrm{mg} / \mathrm{l}$ PHE to the culture medium generally enhanced the extraction yield per cent more than that of control treatments in all explants under both light and darkness. Under light condition, the maximum extraction yield was recorded at $500 \mathrm{mg} / \mathrm{l}$ concentration of PHE, more than that obtained at $1000 \mathrm{mg} / \mathrm{l}$ in all explants.

Table 1. Effect of different concentrations of phenylalanine on the extraction yield (\%) of stem, root and petiole calli of carrot cultures grown on MS supplemented with $1 \mathrm{mg} / \mathrm{l} \mathrm{BAP}+2 \mathrm{mg} / 1 \mathrm{NAA}$ under light and dark conditions. Values are mean \pm standard error of three replicates.

\begin{tabular}{llll}
\hline Callus & PHE & \multicolumn{2}{c}{ Extraction yield $(\% \mathrm{w} / \mathrm{w})$} \\
\cline { 3 - 4 } & $\mathrm{mg} / \mathrm{l}$ & Light & Dark \\
\hline \multirow{3}{*}{ Stem } & 0.0 & $0.36 \pm 0.01$ & $0.63 \pm 0.02$ \\
& 500 & $0.87 \pm 0.03$ & $1.01 \pm 0.07$ \\
& 1000 & $0.78 \pm 0.04$ & $1.08 \pm 0.05$ \\
Root & 0.0 & $0.24 \pm 0.01$ & $0.57 \pm 0.02$ \\
& 500 & $0.9 \pm 0.06$ & $0.8 \pm 0.02$ \\
& 1000 & $0.77 \pm 0.03$ & $1.38 \pm 0.07$ \\
Petiole & 0.0 & $0.42 \pm 0.01$ & $0.67 \pm 0.02$ \\
& 500 & $1.3 \pm 0.07$ & $0.86 \pm 0.05$ \\
LSD $\leq 0.05$ & 1000 & $1.08 \pm 0.06$ & $1.07 \pm 0.06$ \\
\hline
\end{tabular}

In contrast, under dark condition, $1000 \mathrm{mg} / \mathrm{l}$ concentration of phenylalanine gave the maximum value of extraction yield per cent more than recorded at 500 $\mathrm{mg} / \mathrm{l}$ in all explants. Therefore, it's recommended to use phenylalanine at 1000 $\mathrm{mg} / \mathrm{l}$ concentration to enhance the extraction yield of carrot callus. Comparison of PHE supplementation on cell growth has been previously reported in plant cell cultures. Masoumian et al. (2011) discussed the effect of PHE on callus growth and secondary metabolite accumulation (flavonoid) in different plant species. Influence of PHE on biomass depends on its concentration, culture medium, and plant species cultivated in vitro. The authors showed that PHE supplementation (2 to $5 \mathrm{mg} / \mathrm{l}$ ) in Hydrocotyle bonariensis cultures did not significantly influence callus biomass, while in the Artemisia absinthium callus culture, PHE at a concentration less than $33 \mathrm{mg} / \mathrm{l}$ showed a negative effect on cell growth. It's presumed that phenylalanine supplementation increases the metabolic flux through phenyl-propanoid biosynthetic pathway and elevates the 
level of targeted compound (Ouyang et al. 2005). Phenylalanine supplementation has been reported to enhance secondary metabolite production in plant cell cultures (Shinde et al. 2009).

Table 2. Effect of different concentrations of phenylalanine on free radical scavenging capacity of DPPH (\%) for various carrot callus masses grown on MS supplemented with $1 \mathrm{mg} / 1 \mathrm{BAP}+2 \mathrm{mg} / 1 \mathrm{NAA}$ under light and dark conditions. Values are mean \pm standard error of three replicates.

\begin{tabular}{llll}
\hline Callus extract & PHE $(\mathrm{mg} / \mathrm{l})$ & \multicolumn{2}{l}{ Radical scavenging capacity of DPPH, $\%$} \\
\cline { 3 - 4 } & & Light & Dark \\
\hline \multirow{3}{*}{ Stem } & 0.0 & $32.5 \pm 2.94$ & $30.37 \pm 2.82$ \\
& 500 & $37.5 \pm 3.18$ & $61.56 \pm 5.99$ \\
& 1000 & $80.44 \pm 6.99$ & $83.79 \pm 7.87$ \\
\multirow{2}{*}{ Root } & 0.0 & $30.75 \pm 3.01$ & $35.22 \pm 3.05$ \\
& 500 & $55 \pm 4.79$ & $64.37 \pm 5.33$ \\
& 1000 & $70.22 \pm 7.21$ & $106.43 \pm 8.96$ \\
Petiole & 0.0 & $27.22 \pm 1.98$ & $39.75 \pm 3.18$ \\
& 500 & $57.61 \pm 4.92$ & $67.64 \pm 5.86$ \\
LSD $\leq 0.05$ & 1000 & $58.61 \pm 5.04$ & $106.65 \pm 9.81$ \\
\hline
\end{tabular}

A rapid, simple and inexpensive method to measure antioxidant capacity involves the use of the free radical, 2, 2-diphenyl-1-picrylhydrazyl (DPPH). $\mathrm{DPPH}$ radical scavenging activity assay is widely used to test the ability of compounds acting as free radical scavengers or hydrogen donors, evaluating antioxidant activity of food (Lee et al. 2007). It has also been used to quantify antioxidants in complex biological systems in recent years (Gulcin et al. 2004). The degrees of discoloration indicate the radical scavenging capacity of carrot extracts. The effect of antioxidant on DPPH radical scavenging was thought to be due to their hydrogen donating ability (Baumann et al. 1979).

The results demonstrated that the extracts from different explants grown under light conditions exhibited lower DPPH radical scavenging activity at all PHE tested levels compared with those grown under dark conditions. Moreover, under both light and dark conditions callus cultures grown on MS supplemented with $1 \mathrm{mg} / \mathrm{l} \mathrm{BAP}+2 \mathrm{mg} / \mathrm{l}$ NAA plus $1000 \mathrm{mg} / \mathrm{l}$ PHE maximum values of antioxidant activities (Table 2). 
Under dark condition, the DPPH radical scavenging activity was enhanced when carrot callus extracts derived from petiole, root and stem were grown on medium supplemented with $1000 \mathrm{mg} / \mathrm{l}$ PHE (106.65, 106.43 and 83.79\%, respectively), compared with those grown on $500 \mathrm{mg} / \mathrm{l} \operatorname{PHE}(67.64,64.37$ and $61.56 \%$, respectively) and with control treatments (39.75, 35.22 and 30.37, respectively).

On the other hand, under light conditions the DPPH radical scavenging activity gave maximum value with the stem callus extract $(80.44 \%)$ on the medium supplemented with $1000 \mathrm{mg} / \mathrm{l} \mathrm{PHE}$, while petiole callus extract was recorded the minimum DPPH radical scavenging activity $(58.61 \%)$ on medium contained the same precursor concentration compared with control treatment (Table 2).

Determining antioxidant activity of a sample extract based on the overall scavenging effects of DPPH radical is one of the routinely employed antioxidant assays because it is simple, rapid and independent of the polarity of sample extracts. In the present study, scavenging activity against 2, 2'-diphenyl 1picrylhydrazyl radicals (DPPH) was dependent on the explant type, PHE concentration and incubation conditions (light and dark conditions). It may be concluded that the dark conditions gave higher values of antioxidant capacity \% than that of light conditions under the same treatment.

Relative levels of antioxidant activity were determined in several varieties of vegetable families, selected on the basis of their widespread use in traditional consumption via scavenging of 2, 2-diphenyl-2-picryl hydrazylhydrate (DPPH) radical determined spectrophotometrically. A number of carrot species with appreciable levels of antioxidant activity against the DPPH radical were identified as potential sources of free radical scavenging compounds (Miliauskas et al. 2004).

Furthermore, it is important to mention that the accumulation of specific secondary metabolites can be controlled by light (Samuolienè et al. 2013). Light studies in mature plants have demonstrated that light treatments can influence accumulation of carotenoids (Lefsrud et al. 2008, Becatti et al. 2009, Lee et al. 2013).

General antioxidants are induced by light conditions. For example, UV-B and UV-C stimulates phenolics, stilbenes and overall antioxidant activity in pigeon pea (Cajanus cajan) leaves (Colquhoun et al. 2013, Wei et al. 2013). A supplementary UV-B treatment also affects the total antioxidant activity in basil (Sakalauskaitė et al. 2013). 
Table 3._Effect of different concentrations of phenylalanine on inhibition of bleaching $\beta$-carotene linoeic acid $(\%)$ by various carrot callus extract grown on MS supplemented with $1 \mathrm{mg} / 1 \mathrm{BAP}+2 \mathrm{mg} / 1 \mathrm{NAA}$ under light and dark conditions. Values are mean \pm standard error of three replicate.

\begin{tabular}{lllc}
\hline $\begin{array}{l}\text { Callus } \\
\text { extract }\end{array}$ & $\begin{array}{l}\text { PHE } \\
(\mathrm{mg} / \mathrm{l})\end{array}$ & \multicolumn{2}{c}{ Inhibition of bleaching $\beta$-carotene linoeic acid $(\%)$} \\
\cline { 3 - 4 } Stem & 0.0 & $19.32 \pm 1.41$ & Dark \\
& 500 & $37.9 \pm 3.11$ & $26.65 \pm 2.07$ \\
& 1000 & $47.9 \pm 3.96$ & $35.65 \pm 3.15$ \\
\multirow{2}{*}{ Root } & 0.0 & $17.32 \pm 1.57$ & $52.46 \pm 4.99$ \\
& 500 & $22.9 \pm 1.88$ & $22.31 \pm 2.08$ \\
& 1000 & $41.34 \pm 3.75$ & $39.28 \pm 2.84$ \\
Petiole & 0.0 & $13.5 \pm 1.09$ & $72.71 \pm 6.86$ \\
& 500 & $21.36 \pm 1.93$ & $17.26 \pm 1.11$ \\
& 1000 & $39 \pm 3.14$ & $42.32 \pm 3.97$ \\
LSD $\leq 0.05$ & & 13.48 & $73.26 \pm 7.22$ \\
\hline
\end{tabular}

Carotenoids are responsible for the orange color of vegetables, like carrots, and the color intensity is considered a reliable indicator of a higher nutritive value (Goncalves et al. 2010).

The chemical complexity of extracts, often a mixture of dozens of compounds with different functional groups, polarity and chemical behavior, could lead to unpredictable results, depending on the tests employed. Therefore, an approach with multiple assays in the screening work was undertaken (Sacchetti et al. 2005). For that reason and to confirm the important constituents present in carrot callus extracts the $\beta$-carotene bleaching method was applied. Such technique based on the loss of the yellow color of $\beta$-carotene due to its reaction with radicals which formed by linoleic acid oxidation in an emulsion. The rate of $\beta$-carotene bleaching can be slowed down in the presence of antioxidants.

Table 3 shows that the oxidation of the linoleic acid was effectively inhibited by callus extract of the petiole, root and the stem culture in MS supplemented with $1 \mathrm{mg} / \mathrm{l} \mathrm{BAP}+2 \mathrm{mg} / \mathrm{l} \mathrm{NAA}$ plus $1000 \mathrm{mg} / \mathrm{l}$ PHE under dark conditions. Under the light condition the callus extract of stem, root and petiole recorded an inhibition of linolic acid (47.9, 41.43 and 39\%) which is lower compared with dark grown cultures, respectively (52.46, 72.71, and 73.26\%). Meanwhile, the MS supplemented with $1 \mathrm{mg} / \mathrm{l} \mathrm{BAP}+2 \mathrm{mg} / \mathrm{l} \mathrm{NAA}$ plus $500 \mathrm{mg} / \mathrm{l} \mathrm{PHE}$ and the control treatment follows the same pattern of linolic acid inhibition (Table 3). 
The importance of carotenoids in food is immense as natural pigments biological functions and actions have increasingly been attributed to these pigments. In recent years, the consumption of carrot and its products have increased steadily due to their recognition as an important source of natural antioxidants besides possessing anticancer activity of $\beta$-carotene which is a precursor of vitamin A (Dreosti 1993, Speizer et al. 1999).

Table 4. Shows the effect of different concentrations of phenylalanine on total phenolic as gallic acid equivalent for various carrot callus extracts grown on MS supplemented with $1 \mathrm{mg} / 1$ BAP $+2 \mathrm{mg} / 1$ NAA under the light and dark conditions. Values are mean \pm standard error of three replicates.

\begin{tabular}{lllc}
\hline \multirow{2}{*}{$\begin{array}{c}\text { Callus } \\
\text { extract }\end{array}$} & $\begin{array}{l}\text { PHE } \\
(\mathrm{mg})\end{array}$ & \multicolumn{2}{c}{ Total phenolic as gallic acid equivalents (mg/g DW) } \\
\cline { 3 - 4 } Stem & 0.0 & $0.69 \pm 0.063$ & Dark \\
& 500 & $0.87 \pm 0.08$ & $0.72 \pm 0.06$ \\
& 1000 & $2.00 \pm 0.19$ & $1.75 \pm 0.16$ \\
\multirow{3}{*}{ Root } & 0.0 & $0.33 \pm 0.03$ & $2.36 \pm 0.23$ \\
& 500 & $0.46 \pm 0.04$ & $0.51 \pm 0.05$ \\
& 1000 & $0.56 \pm 0.05$ & $0.79 \pm 0.04$ \\
Petiole & 0.0 & $0.43 \pm 0.04$ & $2.23 \pm 0.21$ \\
& 500 & $0.85 \pm 0.08$ & $0.54 \pm 0.06$ \\
& 1000 & $1.19 \pm 0.11$ & $1.12 \pm 0.13$ \\
LSD $\leq 0.05$ & & 0.41 & $3.68 \pm 0.29$ \\
\hline
\end{tabular}

The presence of phenolic compounds in carrot contributes to their sensory qualities such as color (Zhang et al. 2004), bitterness (Kreutzmann et al. 2008), or aroma (Naczk and Shahidi 2003). Therefore, the phenolic compounds could be used as a good indicator to evaluate the superiority of a vegetable under consideration (Goncalves et al. 2010).

Phenolic compounds, especially flavonoids, show various types of biological activity especially its antioxidant property (Smoleń and Sady 2009). The major phenolic compounds in the carrot tissue are chlorogenic, caffeic, and $p$-hydroxybenzoic acids and numerous cinnamic acid derivatives (Torronen et al. 1996).

In the present research, the results are similar to those reported previously. Under light conditions, the total phenolic contents in carrots were reported to be in stem callus cultures as $2.0 \mathrm{mg} / \mathrm{g}$ in dry weight. While under dark conditions 
the highest value of total phenolic was recorded in the petiole callus as $3.68 \mathrm{mg} / \mathrm{g}$ in dry weight as expressed by gallic acid equivalent (GAE). The total phenolic compounds of carrots were found to range from $3.61 \mathrm{GAE} / \mathrm{g}$ to $8.00 \mathrm{GAE} / \mathrm{g}$ in dry matter (Patras et al. 2009), which is comparatively similar to the results obtained in the present set of experiments (Table 4).

A few reports on the antioxidant properties of vegetables have suggested that they are excellent dietary sources of natural antioxidants. Vegetables, including broccoli, carrot, potato and tomato are rich in phenolic compounds, and half of their $\mathrm{MeOH}$ extracts were found to suppress oxidation of lipoproteins in lower density (Zhou and Yu 2006).

Antioxidant and radical scavenging activities in different tissues were found to decrease in the same order as phenolic content. These findings suggest that phenolics play an important role in antioxidant properties in carrots. Therefore, the higher level of phenolics and antioxidant properties in carrot could be considered for value-added utilization. Oviasogie et al. (2009) has reported that the total phenolic content in carrot is $26.6 \pm 1.7 \mu \mathrm{g} / \mathrm{g}$. The total phenols in violet carrot juice have been reported to be $772 \pm 119 \mathrm{mg} / \mathrm{l}$ by Karakaya et al. (2001).

The present work was planted to investigate the antioxidant activity of Daucus carota callus cultures as affected by different PHE concentration under light and dark conditions. Carrot callus cultures were initiated by cultivating different explants on MS medium supplemented with $1 \mathrm{mg} / \mathrm{l} \mathrm{BAP}+2 \mathrm{mg} / \mathrm{l} \mathrm{NAA}$ under light and dark conditions. Derived callus were sub-cultured on the same culture medium fortified with an amino acid precursor, L-phenylalanine (PHE) at different concentrations $(0.0,500$ and $1000 \mathrm{mg} / \mathrm{l})$.

Carrot callus extracts were shown to contain a range of antioxidant molecules and phenolic compounds. The current results support the fact that natural phenolic antioxidants present in carrot callus extracts could be a useful alternative therapy for alleviation of relative oxidative stress. D. carota extracts represent a potential source of phenolic compounds useful for preparation of valuable food supplements.

\section{References}

Alasalvar C, Grigor JM, Zhang D, Quantick PC and Shahidi F (2001): Comparison of volatilves, phenolics, sugars, antioxidant vitamins, and sensory quality of different colored carrot varieties. J. Agri. Food Chem. 49: 1410-1416.

Andlauer W and Furst P (1998): Antioxidative power of phytochemicals with special reference to cereals. Cereal Foods World 43: 356-359. 
Bajaj KL, Kaur G and Sukhija BS (1980) Chemical composition and plant characteristics in relation to quality of some promising cultivars of carrot (Daucus carota L.). Plant Foods Hum. Nutr 30: 97-107.

Baranski R, Allender C and Klimek-Chodacka M (2012): Towards better tasting and more nutritious carrots: carotenoid and sugar content variation in carrot genetic resources. Food Res. Int. 47: 182-187.

Bast A, Van den Berg H, Van der Plas RM and Haenen GRM (1996) $\beta$-Carotene as antioxidant. Eur. J. Clin. Nutr. 50: 554-556.

Baumann J, Wurn G and Bruchlausen FV (1979) Prostaglandin synthetaseinhibiting O2radical scavenging properties of some flavonoids and related phenolic compounds. Naunyn Schmiedebergs Arch Pharmacol. 308: 27-32.

Becatti E, Petroni K and Giuntini D (2009) Solar UV-B radiation influences carotenoid accumulation of tomato fruit through both ethylene-dependent and -independent mechanisms. J. Agric. Food Chem. 57: 10979-10989.

Bendich A (1990) Carotenoids and the immune system. In: Krinsky NI, Mathews-Roth MM, Taylor RF, editors. Carotenoids chemistry and biology. New York: Plenum, pp. 323-335.

Brand-Williams W, Cuvelier ME and Berset C (1995) Use of a free radical method to evaluate antioxidant activity. Lebensmittel Wissenschaft Technologie 28: 25-30.

Byers T and Perry G (1992) Dietary carotenes, vitamin C and vitamin E as protective antioxidants in human cancers. Ann. Rev. Nutr. 12: 139-159.

Castermiller JJM and West CE (1998) Bioavailability and bioconversion of carotenoids. Ann. Rev. Nutr. 18: 19-38.

Colquhoun TA, Schwieterman ML, Gilbert JL, Elizabeth AJ, Kelly ML, Correy RJ, Gabrielle VR, Tia MH , James O, David GC and Kevin MF (2013) Light modulation of volatile organic compounds from petunia flowers and select fruits. Postharvest Biol Technol. 86: 37-44.

Dixon RA and Paiva NL (1995) Stress induced phenolpropanoid metabolism. Plant Cell, 7: 1085-1097.

Dreosti IE (1993) Vitamins A, C, E and beta-carotene as protective factors for some cancers. Asia Pac. J. Clin. Nutr. 2: 5-21.

FAO (2008) Production year book. Rome: Food and Agriculture Organization of the United Nations.

Fontes RR and Vilela NJ (2003): The current status of Brazilian crops and future opportunities. Acta. Hort. 607: 135 -141.

Goncalves EM, Pinheiro J, Abreu M, Brandao TRS, Silva CLM (2010) Carrot (DaucuscarotaL.) peroxidase inactivation, phenolic content and physical changes kinetics due to blanching // Journal of Food Engineering; 97: 574-581. http://dx.doi.org/10.1016/j.jfoodeng.2009.12.005

Grice HC (1986) Safety evaluation of butylatedhydroxytoluene (BHT) in the liver, lung and gastrointestinal tract. Food Chem. Toxicol. 24: 1127-1130. 
Gulcin I, Sat IG, Beydemir S, Elmastas M and Kufrevioglu OI (2004) Comparison of antioxidant activity of clove (Eugenia caryophylataThunb) buds and lavender (Lavandulastoechas L.). Food Chem. 87: 393-400. doi:10.1016/j.foodchem.2003.12.008.

Karakaya S, El SN and Tas AA (2001): Antioxidant activity of some food containing phenolic compounds. Intl. J Food Sci. Nutr. 52: 501-508.

Krinsky NI (1990) Carotenoids in medicine. In: Krinsky NI, Mathews-Roth MM, Taylor RF, Editors. Carotenoids: Chemistry and Biology. New York: Plenum. pp. 279-291.

Kreutzmann S, Christensen LP and Edelenbos M (2008) Investigation of bitterness in carrots (Daucus carotaL.) based on quantitative chemical and sensory analyses. LebensmittelWissenschaftundTechnologie 41(2): 193-205.

Lee BB, Cha MR, Kim SY, Park E, Park HM and Lee SC (2007) Antioxidative and anticancer activity of extracts of cherry (Prunus serratula var. spontanea) blossoms. Plant Food Hum Nutr. 62: 79-84.

Lee WL, Huang JZ, Chen LC, Tsai CC and Chen FC (2013) Developmental and LED light source modulation of carotenogenic gene expression in Oncidiumgowerramsey flowers. Plant Mol. Biol. Rep. 31: 1433-1445.

Lefsrud M, Kopsell D and Sams C (2008): Irradiance from distinct wavelength lightemitting diodes affects secondary metabolites in kale.Hortscience, 43: 2243-2244.

Masoumian M, Arbakariya A, Syahida A and Maziah M (2011) Effect of precursors on flavonoid production byHydrocotylebonariensiscallus tissues. African J. Biotechnol. 10(32): 6021-6029.

Mathews-Roth MM (1985) Carotenoid and cancer prevention-experimental and epidemiological studies. Pure Appl. Chem. 57: 717-722.

Mercier JJ, Arul and J, Julien C (1994) Effect of food preparation on the isocoumarin 6methoxymellein content of UV-treated carrots. Food Res. Int. 27: 401-404.

Michler ChH and Lineberger RD (1987): Effects of Light on Somatic Embryo Development and Abscisic Levels in Carrot Suspension Cultures, Plant Cell Tissue Organ. Culture, 1987, 11, pp. 189-207.

Miliauskas G, Venskutonis PR and VanBeek TA (2004) Screening of radical scavenging activity of some medicinal and aromatic plant extracts. Food Chem. 85: 231-237

Mi-Yac S, Tac-Hum K and Nak-Ju S (2003) Antioxidants and free radical scavenging activity of Phellinusbaumii (Phellinus of Hymeno-Chaetaceae) extracts. Food Chemistry, 82: 593-597.

Murashige T and F Skoog (1962) A revised medium for rapid growth and bio-assays with tobacco tissue cultures. Physiol. Plant. 15(3): 473-497.

Naczk M and Shahidi F (2003) Phenolic compounds in plant foods: chemistry and health benefits. Nutraceut Food 8(2): 200-18.

Namdeo AG, Jadhav TS, Rai PK, Gavali S and Mahadik KR (2007) Precursor feeding for enhanced production of secondary metabolites. Pharmacogn. Rev. 1(2): 227-231.

Nocolle C, Cardinault N, Aprikian O, Busserolles J, Grolier P, Rock E, Demigne C, Mazur A, Scalbert A, Amouroux P and Remesy C (2003) Effect of carrot intake on cholesterol metabolism and antioxidant status in cholesterol fed rats. Eur. J. Nutr. 42: 254-261. 
Patras A, Brunton N, Pieve SD, Butler F and Downey G (2009) Effect of thermal and high pressure processing on antioxidant activity and instrumental colour of tomato and carrot purées // Innovative Food Science and Emerging Technologies. 10: 16-22. http://dx.doi.org/10.1016/j.ifset.2008.09.008

Ouyang J, Wang XD, Zhao B and Wang YC (2005) Enhanced production of phenylethanoid glycosides by precursor feeding to cell culture of Cistanchedeserticola. Process. Biochem. 40: 3480-3484.

Oviasogie OP, Okoro D and Ndiokwere CL (2009) Determination of total phenolic amount of some edible fruits and vegetables. Afr. J. Biotechnol. 8: 2819-2820.

Rao SR and Ravishankar GA (2002) Plant cell cultures: Chemical factories of secondary metabolites. Biotechnol. Adv. 20: 101-153.

Roustan JP, Latche, A and Fallot J (1990) Inhibition of ethylene production and stimulation of carrot somatic embryogenesis by salicylic acid. Biol. Plant. 32: 273-276.

Rubatzky VE, Quiros CF and Simon PW (1999) Carrots and related vegetable Umbelliferae. CABI Pub, New York; Wallingford, Oxon, UK.

Sacchetti G, Maietti S, Muzzoli M, Scaglianti M, Manfredini S, Radice M and Bruni R (2005) Comparative evaluation of 11 essential oils of different origin as functional antioxidants, antiradicals and antimicrobials in foods. Food Chem. 91: 621-632.

Sakalauskaitè J, Viskelis P and Dambrauskienè E (2013):The effects of different UV-B radiation intensities on morphological and biochemical characteristics in Ocimum basilicum L. J .Sci Food Agric. 93: 1266-1271.

Samuolienè G, Brazaitytè A and Jankauskienè J (2013) LED irradiance level affects growth and nutritional quality of Brassica microgreens. Cent Eur J Biol. 8: 1241-1249.

Santo MS, Leka L, Fotouhi N, Meydani M, Hennekens GH, Meydani SN, Wu D and Gaziano JM (1996) Natural killer cell activity in elderly men is enhanced by $\beta$ carotene supplementation. Am J Clin Nutr. 64: 772-777.

Shinde AN, Malpathak N and Fulzele DP (2009) Enhanced production of phytoestrogenicisoflavones from hairy root cultures of Psoralea corylifolia L. using elicitation and precursor feeding. Biotechnol. Bioprocess Eng. 14: 288-294.

Simon, PW (2000): Domestication, historical development, and modern breeding of carrot. Plant Breed. Rev. 19: 157-190.

Singh G, Kawarta A and Sehgal S (2001) Nutritional composition of selected green leafy vegetables, herbs and carrots. Plant Foods Hum Nutr. 56: 359-364.

Smolen S and Sady W (2009): The effect of various nitrogen fertilization and foliar nutrition regimes on the concentrations of sugars, carotenoids and phenolic compounds in carrot (DaucuscarotaL.), Scientia Horticulturae 120(13): 315-324.

http://dx.doi.org/10.1016/j.scienta.2008.11.029

Speizer FE, Colditz GA, Hunter DJ, Rosner B and Hennekens C (1999) Prospective study of smoking, antioxidant intake and lung cancer in middle aged women. Cancer Causes Control. 10: 475-482.

Stintzing FC and Carle R (2004):Functional properties of anthocyanins and betalains in plants, food, and in human nutrition. Trends Food Sci. Technol. 15: 19-38. 
Tevfik, O and Kadir K (2008) Determination of antioxidant activity of various extracts of Parmeliasaxatilis, Biologia 63(2): 211-216.

Torronen R, Lehmusaho M, Hakkinen S, Hanninen O and Mykkanen H (1996) Serum $\beta$-carotene response to supplementation with raw carrots, carrot juice or purified $\beta$ carotene in healthy non-smoking women. Nutr. Res. 16: 565-575.

Van den Berg H, Faulks R, Granado HF, Hirschberg J, Olmedilla B, Sandmann G, Southon S and Stahl W (2000) The potential for the improvement of carotenoid levels in foods and the likely systemic effects. J. Sci. Food Agri. 80: 880-912.

Van PG (1996) Review: epidemiological evidence for $\beta$-carotene in prevention of cancer and cardiovascular disease. Eur. J. Clin. Nutr. 50: 557-561.

Vilela NJ (2004) Cenoura: um alimentonobrena mesa popular. HorticulturaBrasileira 22: cover article.

Wei ZF, Luo M and Zhao CJ (2013): UV-induced changes of active components and antioxidant activity in postharvest pigeon pea [Cajanuscajan (L.) Millsp.] Leaves. J. Agric Food Chem. 61: 1165-1171.

Wichi HP (1988) Enhanced tumor development by butylatedhydroxyanisol (BHA) from the prospective of effect on forestomach and oesophageal squamous epithelium. Food Chem. Toxicol. 26: 717-723.

Widholm JM (1984) Carrot Cell Mutants, Plant Mol. Biol. Report. , 2(3): pp. 45-53.

Zheng W and Wang SY (2001) Antioxidant activity and phenolic compounds in selected herbs. J. Agric. Food Chem. 49: 5165-5170.

Zhou K and Yu L (2006) Total phenolic contents and antioxidant properties of commonly consumed vegetables grown in Colorado // LWT - Food Science and Technology; 39: 1155-1162. http://dx.doi.org/10.1016/j.lwt.2005.07.015 